\title{
Chemotherapy-induced peripheral neuropathy after neoadjuvant or adjuvant treatment of breast cancer: a prospective cohort study
}

\author{
Susana Pereira $^{1,2}$ - Filipa Fontes ${ }^{2,3} \cdot$ Teresa Sonin $^{1} \cdot$ Teresa Dias $^{1} \cdot$ Maria Fragoso $^{1}$. \\ José M. Castro-Lopes ${ }^{4,5} \cdot$ Nuno Lunet ${ }^{2,3}$
}

Received: 26 March 2015 / Accepted: 2 September 2015 /Published online: 18 September 2015

(C) Springer-Verlag Berlin Heidelberg 2015

\begin{abstract}
Purpose The purposes of this study were to estimate the incidence of chemotherapy-induced peripheral neuropathy (CIPN) and to identify its main determinants and impact in patient-reported outcomes.

Methods We performed a prospective cohort study including 296 patients with incident breast cancer submitted to chemotherapy, followed for 1 year. Patients with incident CIPN were reevaluated 6 months after this diagnosis. Relative risks (RR) with $95 \%$ confidence intervals $(95 \% \mathrm{CI})$ were computed to quantify the relation between different clinical characteristics and the occurrence of CIPN, using Poisson regression. The variation of patient-reported outcomes between baseline and 1-year follow-up assessments was compared between patients with and without CIPN.

Results The cumulative incidence of CIPN in the first year after diagnosis was $28.7 \%$ (95\% CI 23.8-34.1), and more than $80 \%$ of the patients were still symptomatic after 6 months. Among the latter, there was a significant decrease
\end{abstract}

Nuno Lunet

nlunet@med.up.pt

1 Portuguese Institute of Oncology of Porto, Rua Dr. António Bernardino de Almeida, 4200-075 Porto, Portugal

2 EPIUnit - Institute of Public Health, University of Porto (ISPUP), Rua das Taipas, n 135, 4050-600 Porto, Portugal

3 Department of Clinical Epidemiology, Predictive Medicine and Public Health, Faculty of Medicine, University of Porto, Al. Prof. Hernâni Monteiro, 4200-319 Porto, Portugal

4 Department of Experimental Biology, Faculty of Medicine, University of Porto, Al. Prof. Hernâni Monteiro, 4200-319 Porto, Portugal

5 Institute for Molecular and Cell Biology (IBMC), University of Porto, Rua do Campo Alegre, n 823, 4150-180 Porto, Portugal in the median total neuropathy score, clinical version (7 versus 4) between the two periods. In multivariable analysis, the risk of CIPN was higher for treatment with docetaxel (cumulative doses $\leq 300 \mathrm{mg} / \mathrm{m}^{2}, \mathrm{RR}=6.96,95 \%$ CI $2.53-19.10 ;>300 \mathrm{mg} /$ $\mathrm{m}^{2}, \mathrm{RR}=13.32 ; 95 \% \mathrm{CI}$ 4.11-43.14). Alcohol consumption and diabetes were not significantly associated with CIPN. There were no significant differences in the variation of patient-reported outcomes between the baseline and 1-year follow-up evaluations.

Conclusions CIPN was frequent in this contemporary cohort of early-stage breast cancer patients and was strongly associated with docetaxel-based regimens. Symptoms persisted for at least 6 months in most patients, but severity was low and CIPN had no impact on patient-reported outcomes.

Keywords Breast neoplasm · Peripheral nerve injuries · Quality of life

\section{Introduction}

Breast cancer is the most frequent cancer in women, with an estimated 1.7 million new cases diagnosed in 2012 [1] and is among those with better survival (the 5 -year relative survival is higher than $80 \%$ in most developed countries $[2,3])$. The growing number of women living for increasingly long periods after the diagnosis of breast cancer highlights the need of a comprehensive assessment of the burden of the disease related with breast cancer treatments among survivors. Chemotherapy-induced peripheral neuropathy (CIPN) is one of the most frequent adverse effects of many commonly used chemotherapeutic agents [4], with potential impact on the patients' quality of life (QoL) [5, 6].

CIPN involve the peripheral nervous system and lead to predominantly sensory peripheral neuropathy, with a 
"stocking and glove" distribution characterized by sensory loss, paresthesia, numbness, and tingling, that may be aggravated by neuropathic pain $[7,8]$. Treatments associated with a higher incidence of CIPN include those with platinum drugs, vinca alkaloids, or taxanes [9]. The estimated occurrence of CIPN among patients undergoing chemotherapy varied widely across previous investigations, largely reflecting differences in study designs, populations studied, specificities of the treatment schemes, and lack of uniformity in CIPN assessment methods [10-14].

Preexisting peripheral neuropathies, namely due to diabetes or excessive alcohol consumption have been considered risk factor for CIPN. Although these associations seem plausible, because such conditions can cause a neuropathy similar to CIPN, their role as risk factors for CIPN is not yet demonstrated since most previous investigations excluded these patients and the few existing studies have conflicting results [15-18] and, to our knowledge, the available results do not refer specifically to breast cancer patients.

A prospective study with a systematic neurological evaluation of patients during different moments of the first year after breast cancer diagnosis, and a standardized clinical assessment and characterization of CIPN among patients in early stages, treated with different chemotherapy schemes, may contribute to a better understanding of the burden of this neurological complication. Therefore, we aimed to estimate CIPN incidence and to identify its main determinants and impact in different patient-reported outcomes.

\section{Methods}

\section{Study design and participants}

We conducted a prospective cohort study of women consecutively recruited in 2012 among those with newly diagnosed breast cancer admitted to the Breast Clinic of the Portuguese Institute of Oncology of Porto, Portugal. The study methods have been described in detail elsewhere [19]. Briefly, we consecutively selected women proposed for surgery, either as primary treatment or after neoadjuvant chemotherapy, whose follow-up would go on to occur in the same hospital. We excluded those previously treated for cancer, submitted to breast surgery, with stage IV breast cancer, and those scoring less than 17, or less than 16 for women over 65 years old in the Montreal Cognitive Assessment (MoCA), which was assumed to correspond to a high probability of cognitive impairment [20].

The cohort included 502 patients with incident breast cancer, from whom 296 (59.0 \%) underwent neoadjuvant or adjuvant chemotherapy in the first year after diagnosis and therefore were considered for the present analysis.

\section{Data collection}

All patients underwent a neurological evaluation and sociodemographic and medical data were collected at baseline (before any treatment), 2 weeks after surgery, 3 weeks after the last cycle of chemotherapy, and 1 year after enrolment. Patients diagnosed with CIPN during the first year of follow-up were also evaluated at the moment of CIPN confirmation and after 6 months, in order to define the chronicity of such condition.

At baseline, information on the consumption of alcoholic beverages and previous diagnosis of diabetes or thyroid pathology was obtained from the patients and/or review of their medical records. Self-report or record of either a previous diagnosis or treatment with insulin or oral antidiabetic drugs were considered to classify patients as having diabetes. Individuals drinking at least one alcoholic drink per month were classified as current drinkers and those who stopped drinking at least 6 months before the interview as former drinkers. Current drinkers were further classified according to the amount of ethanol consumed; for this purpose, we considered that a standard drink corresponds to $14 \mathrm{~g}$ of ethanol.

Preexisting cases of peripheral neuropathy were identified at the baseline neurological assessment. During the remaining evaluations, data about breast cancer stage, surgery, chemotherapy (including chemotherapy schemes and total dose delivered), and other adjuvant treatments performed were collected from clinical records by clinicians.

Patient-reported outcomes were evaluated before any treatment and at 1 year after enrolment. QoL was assessed using the self-administered questionnaire of the European Organization for the Research and Treatment of Cancer (EORTC) (QLQ-C30) [21]; the specific global health status/QoL subscale was used for the purpose of this study. Sleep quality was evaluated using the Pittsburg Sleep Quality Index (PSQI) [22]. Anxiety and depression were evaluated using the Hospital Anxiety and Depression Scale (HADS) [23]. For the global health status/QoL subscale, higher scores represent a healthier level of QoL, while in the remaining instruments, higher scores correspond to worse outcomes.

\section{Outcome definition}

CIPN was defined as peripheral neuropathy beginning after chemotherapy; among patients with preexisting peripheral neuropathy, CIPN was considered to have occurred only if there was a worsening of neuropathy after the beginning of chemotherapy. CIPN was quantified using the Common Terminology Criteria for Adverse Events version 4.0 (CTCAE v4.0) [24] and the Total Neuropathy Score, clinical version (TNSc) [25]. The latter requires that strength, deep tendon reflexes, vibration sensibility (128-Hz tuning fork), and pain sensation (wood cocktail-stick) are evaluated to quantify the 
severity of neuropathy. The classification system proposed by the International Association for the Study of Pain (IASP) was used in order to classify painful CIPN [26].

Incident cases of CIPN were identified through referral by any member of the clinical team or during the systematic neurological evaluations performed by neurologists. Cases identified at the time of the scheduled follow-up evaluations were assigned an estimated date of onset based on information provided by the patients. When applicable, information regarding chemotherapy interruption or dose reduction was retrieved from records.

\section{Statistical analysis}

We computed cumulative incidence estimates for CIPN at the 1 -year follow-up and the corresponding $95 \%$ confidence intervals $(95 \% \mathrm{CI})$.

Crude and adjusted relative risks (RR) and corresponding $95 \%$ CI for the relation between different characteristics of the patients and the occurrence of CIPN in the first year after enrolment were computed using Poisson regression; variables included in each model are described in the footnotes of the corresponding table.

Standardized scores ( $z$ scores) of the variation in patientreported outcomes between the baseline assessment and the 1year follow-up evaluation were computed.

Statistical analysis was conducted using STATA ${ }^{\circledR}$, version 11.2 (StataCorp, College Station, TX, USA).

\section{Results}

Figure 1 depicts the number of patients in each evaluation performed. From those who underwent chemotherapy, one patient abandoned the study (no reason specified), and 295
$(99.7 \%)$ completed the 1-year follow-up evaluation. A total of 85 patients were diagnosed with CIPN and all completed the 6-month evaluation after diagnosis.

\section{Patients' characteristics}

The main demographic and medical characteristics of the participants are presented in Table 1. At baseline, 46.0\% were aged less than 50 years and $70.3 \%$ had up to 9 years of education. Approximately one third of women were diagnosed with breast cancer stage I, and most patients performed chemotherapy as adjuvant treatment $(88.8 \%)$. The most frequent chemotherapy scheme performed was FEC-D [three cycles of concomitant 5-fluorouracil (5-FU) $500 \mathrm{mg} / \mathrm{m}^{2}$, epirubicin $100 \mathrm{mg} / \mathrm{m}^{2}$, and cyclophosphamide $500 \mathrm{mg} / \mathrm{m}^{2}$ followed by three cycles of docetaxel $\left.100 \mathrm{mg} / \mathrm{m}^{2}\right]$. In addition to chemotherapy, endocrine therapy and radiotherapy were the most common adjuvant treatments (83.7 and $83.4 \%$, respectively).

\section{Incidence and characterization of CIPN}

During the first year after the diagnosis of breast cancer, $28.7 \%$ (95 \% CI 23.8-34.1) of the patients were diagnosed with CIPN. Among those submitted to docetaxel-based regimens, the cumulative incidence was 38.0\% (95\% CI 31.844.7). The median [percentile 25-percentile 75 (P25-P75)] time to CIPN onset since the beginning of chemotherapy was 107 (84-122) days.

At the moment of CIPN diagnosis, all patients presented peripheral sensory neuropathy grade 1 or 2 but only $18.8 \%$ had motor neuropathy (grade 1 to 3 ), according to the CTCAE $\mathrm{v} 4.0$; the TNSc ranged between 3 and 12 (Table 2). Five patients presented painful CIPN, classified as probable according to the IASP; only one patient required dose reduction due

Fig. 1 Flow chart describing the number of patients in each of the evaluations performed. $C I P N$ chemotherapy-induced peripheral neuropathy, $P 25$ percentile 25 , $P 75$ percentile 75
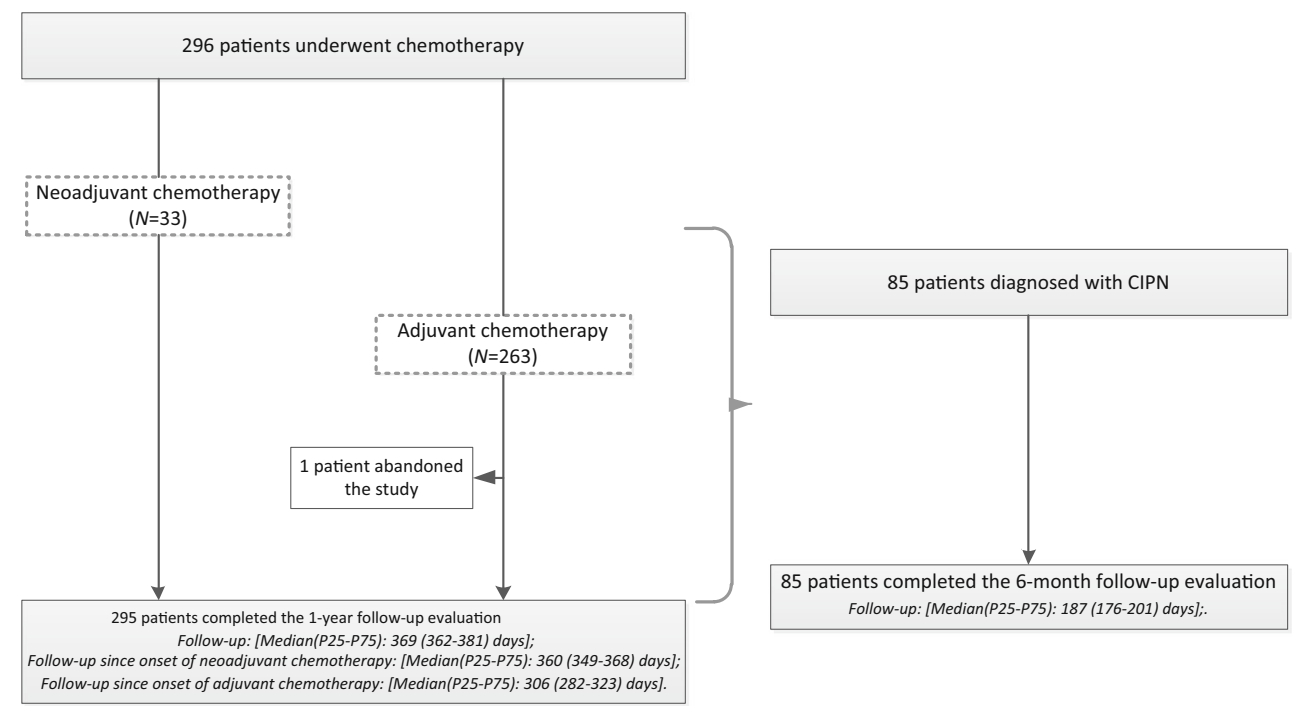
Table 1 Demographic and medical characteristics of the breast cancer patients submitted to chemotherapy $(N=296)$

\begin{tabular}{|c|c|c|}
\hline & & $N(\%)^{\mathrm{a}}$ \\
\hline Age, years [mean (SD)] & & $52.0(10.1)$ \\
\hline \multirow[t]{2}{*}{ Age, years } & $<50$ & $136(46.0)$ \\
\hline & $\geq 50$ & $160(54.0)$ \\
\hline Education, years [median (P25-P75)] & & $6.0(4.0-11.5)$ \\
\hline \multirow[t]{4}{*}{ Education, years } & $\leq 4$ & $103(34.8)$ \\
\hline & $5-9$ & $105(35.5)$ \\
\hline & $10-12$ & $47(15.9)$ \\
\hline & $>12$ & $41(13.8)$ \\
\hline \multirow[t]{3}{*}{ Medical comorbidities } & Thyroid pathology & $41(13.8)$ \\
\hline & Diabetes & $20(6.8)$ \\
\hline & Preexisting peripheral neuropathy & $2(0.7)$ \\
\hline \multirow[t]{3}{*}{ Cancer stage at baseline } & I & $95(32.1)$ \\
\hline & II & $132(44.6)$ \\
\hline & III & $69(23.3)$ \\
\hline \multicolumn{3}{|l|}{ Surgery } \\
\hline \multirow[t]{2}{*}{ Breast surgery $^{\mathrm{b}}$} & Mastectomy & $165(55.7)$ \\
\hline & Breast-conserving & $131(44.3)$ \\
\hline \multirow[t]{2}{*}{ Axillary surgery $^{\mathrm{c}}$} & ALND & $154(52.0)$ \\
\hline & SLNB & $142(48.0)$ \\
\hline \multicolumn{3}{|l|}{ Chemotherapy } \\
\hline \multirow[t]{2}{*}{ Timing of chemotherapy } & Neoadjuvant & $33(11.2)$ \\
\hline & Adjuvant & $263(88.8)$ \\
\hline \multirow[t]{8}{*}{ Chemotherapy schemes ${ }^{\mathrm{d}}$} & Doxorubicin + cyclophosphamide $^{\mathrm{e}}$ & $57(19.3)$ \\
\hline & Doxorubicin + cyclophosphamide $+\operatorname{docetaxel}^{\mathrm{f}}$ & $32(10.8)$ \\
\hline & Doxorubicin + cyclophosphamide + paclitaxel $^{\mathrm{g}}$ & $1(0.3)$ \\
\hline & Cyclophosphamide + docetaxel $^{\mathrm{h}}$ & $2(0.7)$ \\
\hline & Carboplatin + docetaxel $^{\mathrm{i}}$ & $1(0.3)$ \\
\hline & 5-FU+epirubicin + cyclophosphamide $^{j}$ & $24(8.1)$ \\
\hline & 5-FU + epirubicin + cyclophosphamide + docetaxel $^{\mathrm{k}}$ & $178(60.1)$ \\
\hline & $5-\mathrm{FU}+$ cyclophosphamide + methotrexate $^{1}$ & $1(0.3)$ \\
\hline \multirow[t]{4}{*}{ Other adjuvant treatments $\left[N=295^{\mathrm{m}}\right]$} & Radiotherapy & $246(83.4)$ \\
\hline & Brachytherapy & $43(14.5)$ \\
\hline & Endocrine therapy & $247(83.7)$ \\
\hline & Immunotherapy & $68(23.0)$ \\
\hline
\end{tabular}

$A L N D$ axillary lymph node dissection, $P 25$ percentile $25, P 75$ percentile $75, S D$ standard deviation, $S L N B$ sentinel lymph node biopsy, 5-FU 5fluorouracil

${ }^{\text {a }}$ Results are presented as $N(\%)$, except if otherwise specified

${ }^{\mathrm{b}}$ Patients who had both mastectomy and breast-conserving surgery are reported as mastectomy

${ }^{\mathrm{c}}$ Patients who had both ALND and SLNB are reported as ALND

${ }^{\mathrm{d}}$ Does not sum $100.0 \%$ due to rounding

${ }^{\mathrm{e}}$ Four cycles of concomitant doxorubicin $\left(60 \mathrm{mg} / \mathrm{m}^{2}\right)$ and cyclophosphamide $\left(600 \mathrm{mg} / \mathrm{m}^{2}\right)$

${ }^{\mathrm{f}}$ Four cycles of concomitant doxorubicin $\left(60 \mathrm{mg} / \mathrm{m}^{2}\right)$ and cyclophosphamide $\left(600 \mathrm{mg} / \mathrm{m}^{2}\right)$, followed by four cycles of docetaxel $\left(100 \mathrm{mg} / \mathrm{m}^{2}\right)$

${ }^{\mathrm{g}}$ Four cycles of concomitant doxorubicin $\left(60 \mathrm{mg} / \mathrm{m}^{2}\right)$ and cyclophosphamide $\left(600 \mathrm{mg} / \mathrm{m}^{2}\right)$, followed by four cycles of paclitaxel $\left(80 \mathrm{mg} / \mathrm{m}^{2}\right)$

${ }^{\mathrm{h}}$ Four cycles of concomitant cyclophosphamide $\left(600 \mathrm{mg} / \mathrm{m}^{2}\right)$ and docetaxel $\left(75 \mathrm{mg} / \mathrm{m}^{2}\right)$

${ }^{\mathrm{i}} \mathrm{Six}$ cycles of concomitant docetaxel $\left(75 \mathrm{mg} / \mathrm{m}^{2}\right)$ and carboplatin $\left(212 \mathrm{mg} / \mathrm{m}^{2}\right)$

${ }^{\mathrm{j}}$ Six cycles of concomitant 5 -FU $\left(500 \mathrm{mg} / \mathrm{m}^{2}\right)$, epirubicin $\left(100 \mathrm{mg} / \mathrm{m}^{2}\right)$, and cyclophosphamide $\left(500 \mathrm{mg} / \mathrm{m}^{2}\right)$

${ }^{\mathrm{k}}$ Three cycles of concomitant 5-FU $\left(500 \mathrm{mg} / \mathrm{m}^{2}\right)$, epirubicin $\left(100 \mathrm{mg} / \mathrm{m}^{2}\right)$, and cyclophosphamide $\left(500 \mathrm{mg} / \mathrm{m}^{2}\right)$ followed by three cycles of docetaxel $\left(100 \mathrm{mg} / \mathrm{m}^{2}\right)$

${ }^{1}$ Six cycles of concomitant 5 -FU $\left(600 \mathrm{mg} / \mathrm{m}^{2}\right)$, cyclophosphamide $\left(600 \mathrm{mg} / \mathrm{m}^{2}\right)$, and methotrexate $\left(40 \mathrm{mg} / \mathrm{m}^{2}\right)$

${ }^{\mathrm{m}}$ Data is only available for patients who completed the 1-year follow-up evaluation 
Table 2 Classification of chemotherapy-induced peripheral neuropathy $(N=85)$

\begin{tabular}{|c|c|c|c|c|c|}
\hline & & \multicolumn{4}{|l|}{$N(\%)^{\mathrm{a}}$} \\
\hline & & \multirow{2}{*}{$\begin{array}{l}\text { All patients with a diagnosis of CIPN }(N=85) \\
\text { Baseline }\end{array}$} & \multicolumn{3}{|c|}{ Patients with CIPN lasting at least 6 months $(N=70)$} \\
\hline & & & Baseline & 6-month follow-up & $P$ value \\
\hline \multirow{5}{*}{$\begin{array}{l}\text { Peripheral motor neuropathy } \\
\text { (according to CTCAE v4.0) }\end{array}$} & Absent & $69(81.2)$ & $57(81.4)$ & $65(92.9)$ & \\
\hline & Present & $16(18.8)$ & $13(18.6)$ & $5(7.1)$ & \\
\hline & Grade 1 & $10(11.8)$ & $7(10.0)$ & $4(5.7)$ & \\
\hline & Grade 2 & $5(5.9)$ & $2(7.1)$ & $0(0.0)$ & $0.057^{\mathrm{b}}$ \\
\hline & Grade 3 & $1(1.2)$ & $1(1.4)$ & $1(1.4)$ & \\
\hline \multirow{4}{*}{$\begin{array}{l}\text { Peripheral sensory neuropathy } \\
\text { (according to CTCAE v4.0) }\end{array}$} & Absent & $0(0.0)$ & $0(0.0)$ & $1(1.4)$ & \\
\hline & Present & $85(100.0)$ & $70(100.0)$ & $69(98.6)$ & \\
\hline & Grade 1 & $57(67.1)$ & $43(61.4)$ & $54(77.1)$ & \\
\hline & Grade 2 & $28(32.9)$ & $27(38.6)$ & $15(21.4)$ & $0.017^{\mathrm{c}}$ \\
\hline \multicolumn{6}{|l|}{ Total neuropathy score } \\
\hline Median (P25-P75) & & $6(5-9)$ & $7(5-9)$ & $4(2-6)$ & $<0.001$ \\
\hline Range & & 3 to 12 & 3 to 12 & 1 to 13 & \\
\hline
\end{tabular}

CTCAE v4.0 Common Terminology Criteria for Adverse Events, version 4.0, P25 percentile 25, P75 percentile 75

${ }^{\text {a }}$ Results are presented as $N(\%)$, except if otherwise specified

${ }^{\mathrm{b}} \mathrm{McNemar}$ exact test for the comparison of the proportion of patients with motor symptoms

${ }^{\mathrm{c}} \mathrm{McNemar}$ exact test for the comparison of the proportion of patients with sensory symptoms grade 2

to CIPN and there were no cases of discontinuation related to CIPN.

\section{Predictors of CIPN during the first year of follow-up}

Table 3 presents RR for the relation between different characteristics of the patients and the occurrence of CIPN during the first year after enrolment. Compared to chemotherapy schemes with no docetaxel, patients treated with a cumulative dose of docetaxel $\leq 300 \mathrm{mg} /$ $\mathrm{m}^{2}$ had a nearly sevenfold higher risk of CIPN $(\mathrm{RR}=$ 6.96 ; $95 \%$ CI 2.53-19.10), and among those receiving $>300 \mathrm{mg} / \mathrm{m}^{2}$, the risk was more than 13 times higher $(\mathrm{RR}=13.32 ; 95 \%$ CI 4.11-43.14).

In multivariate analyses, cancer stage III $(\mathrm{RR}=2.45 ; 95 \%$ CI 1.36-4.04), axillary lymph node dissection (ALND) $(\mathrm{RR}=$ 2.28; $95 \%$ CI 1.23-4.25), and immunotherapy $(\mathrm{RR}=1.96$; $95 \%$ CI 1.24-3.09) were also associated with a higher risk of CIPN. However, after adjusting for chemotherapy drugs, cancer stage III $(\mathrm{RR}=1.01 ; 95 \%$ CI 0.51-1.98), ALND $(\mathrm{RR}=$ 1.24 ; $95 \%$ CI $0.65-1.98)$, and immunotherapy $(\mathrm{RR}=1.43$; $95 \%$ CI 0.88-2.33) were no longer associated with the occurrence of CIPN.

Diabetes and alcohol consumption habits at baseline were not significantly associated with the occurrence of CIPN (Table 3), and the RR estimates for the relation between docetaxel-based chemotherapy and CIPN did not change meaningfully when further adjusted for diabetes or alcohol consumption (7.22 vs. 7.09).

\section{Impact of CIPN in patient-reported outcomes at 1-year follow-up}

The variation of $z$ scores of patient-reported health-related outcomes, between the baseline and the 1-year follow-up assessment, according to the presence of CIPN is represented in Fig. 2. There were no statistically significant differences in the variation between the two moments of evaluation according to the presence of CIPN. Also, there were no statistically significant differences in the variation of any of the patient reported outcomes according to the presence of motor neuropathy or the severity of CIPN (data not shown).

\section{CIPN during the 6-month follow-up of CIPN patients}

A total of $70(82.4 \%, 95 \%$ CI $72.8-89.1)$ of all patients with CIPN remained symptomatic to the end of the follow-up of the subcohort.

As depicted in Table 2, among those symptomatic at the 6month follow-up, there was a decrease in the severity of motor (present in 18.6 and $7.1 \%$ of the patients at baseline and follow-up, respectively; $P=0.057$ ) and sensory symptoms (grade 2 in 38.6 and $21.4 \%$ of the patients at baseline and follow-up, respectively; $P=0.017$ ) during the follow-up. The 


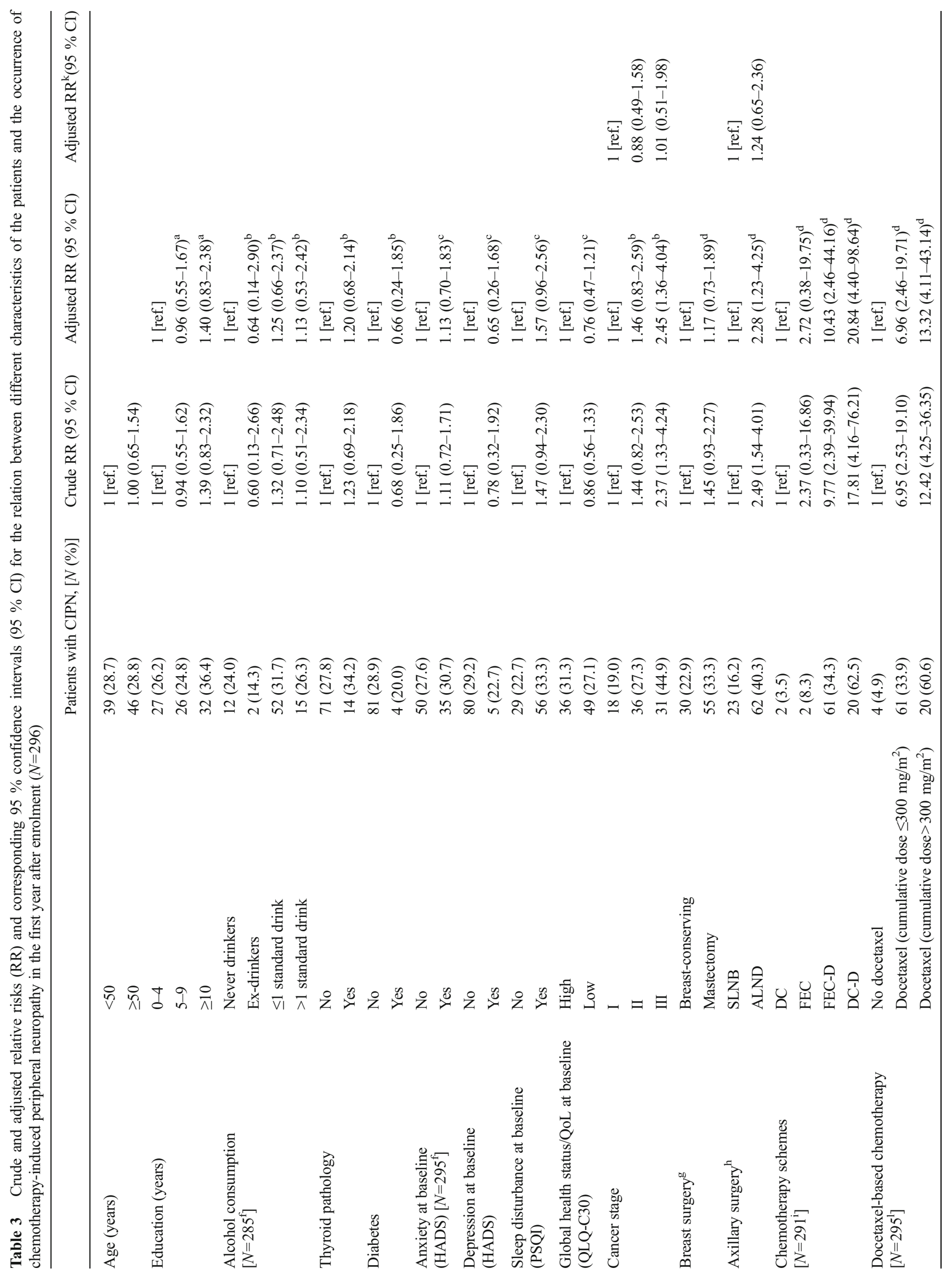




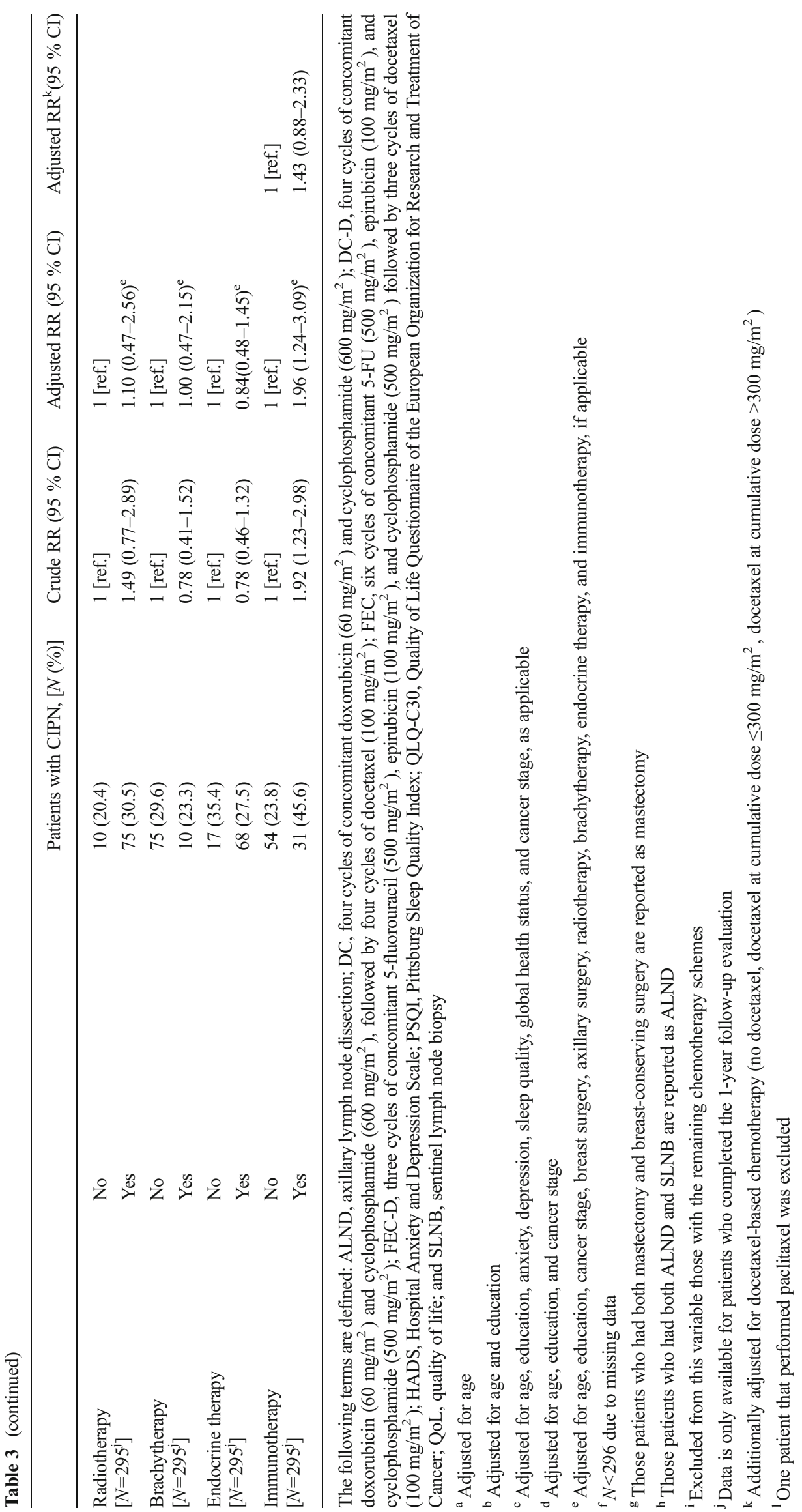




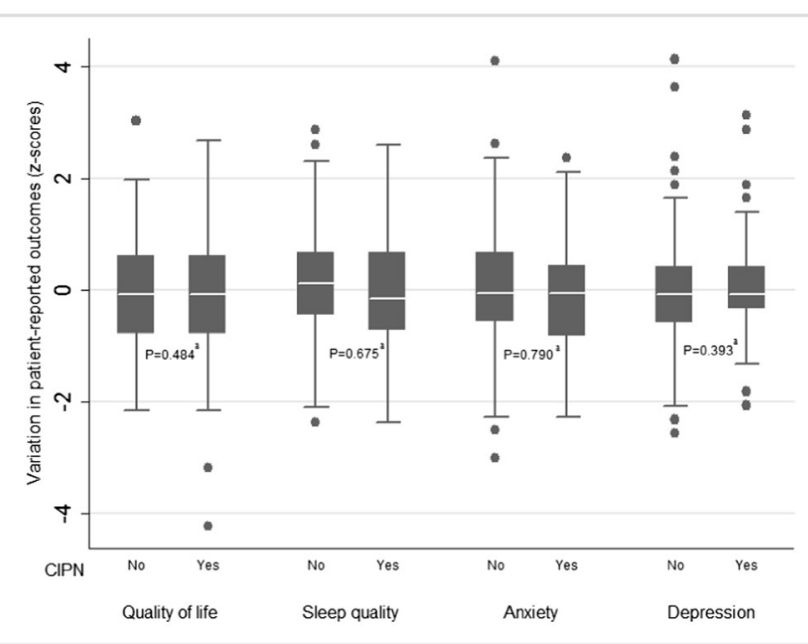

Fig. 2 Variation in patient-reported outcomes between the baseline and the 1-year follow-up assessment, according to the presence of CIPN. Superscript a, Mann-Whitney $U$ test. $C I P N$ chemotherapy-induced peripheral neuropathy

median (P25-P75) TNSc decreased significantly from 7 (5-9) to 4 (2-6).

In crude and multivariate analyses, sociodemographic and medical characteristics (including breast cancer treatments) and patient-reported outcomes at baseline were not associated with higher risk of CIPN after 6 months of the diagnosis of this complication (data not shown).

\section{Discussion}

The present study provides a comprehensive assessment of the clinical epidemiology of CIPN after neoadjuvant and adjuvant treatments of breast cancer, in a contemporary cohort of women with early-stage cancer. Important strengths of this investigation are the nearly complete follow-up of the main cohort and a complete follow-up of the CIPN patients. Furthermore, the use of the TNSc to grade CIPN has the advantage of including an objective nerve function examination [25, 27]. Peripheral neuropathy is a major complication of both diabetes and alcoholism and both have been assumed in the literature as risk factors for CIPN $[28,29]$. To our knowledge, this is the first prospective study addressing diabetes and alcohol consumption as risk factors for CIPN in breast cancer patients. However, we did not find a significant association between these two exposures and CIPN or its severity (data not shown). These results suggest that alcohol consumption and diabetes have no important effect in the occurrence of CIPN, at least among patients with relatively low alcohol intake and type 2 controlled diabetes mellitus, such as those in the present cohort. Unfortunately, it was not possible to assess the effect of previous neuropathy in the occurrence of CIPN because the number of patients with neuropathy at baseline was too small.
There were only two patients with mild diabetic neuropathy diagnosed at baseline, and these were not treated with docetaxel.

Nearly $30 \%$ of the patients developed CIPN within 1 year of breast cancer diagnosis, and the cumulative incidence of docetaxel-induced peripheral neuropathy was $38.0 \%$. Our data yielded estimates of the frequency of docetaxel-induced peripheral neuropathy similar to those found by other authors in Denmark [30,31], but in our cohort all women with CIPN had sensory symptoms up to grade 2, whereas in the former investigations, the proportion of cases graded higher than 2 was $7.7 \%$ [31] and $32.5 \%$ [30]. However, one of these studies excluded women with sensory neuropathy grade 1 and relied on self-reports to define CIPN [30], the other identified and characterized CIPN using retrospective clinical record data [31], and both used version 2.0 of the CTCAE to assess the severity of CIPN. Regarding motor symptoms, its occurrence has been described to be less frequent than sensory neuropathy $[4,32]$, which was in accordance with our results.

Higher doses per cycle [30] and cumulative doses over $600 \mathrm{mg} / \mathrm{m}^{2}$ [28] have been described as risk factors for docetaxel-induced peripheral neuropathy, though a more recent study, with patients that underwent cumulative doses less than $450 \mathrm{mg} / \mathrm{m}^{2}$, did not find a dose-response relationship [30]. In our cohort, compared to chemotherapy schemes with no docetaxel, patients treated with a cumulative dose of docetaxel $\leq 300 \mathrm{mg} / \mathrm{m}^{2}$ had a nearly sevenfold higher risk of CIPN, and the RR was just over 13 times higher for those receiving $>300 \mathrm{mg} / \mathrm{m}^{2}$. Unfortunately, the present study does not allow an assessment of the impact of dose-dense regimens in the incidence of CIPN since the use of this treatment strategy in the institution where patients were recruited started approximately 2 years after the baseline assessment.

A systematic review addressing the role of CIPN on QoL among cancer patients found a probable negative association with QoL [33]. Of the 11 studies assessing the association of CIPN on patients' QoL, three did not find an association and the others concluded that CIPN was associated with a lower QoL. However, none of the studies included specifically women with breast cancer. A recent study in early breast cancer patients that underwent chemotherapy with docetaxel found that the persistence of CIPN 1-3 years after treatment had a significant negative correlation with health-related QoL [6]. In our study, we did not find a significant impact of CIPN in patient-reported outcomes at 1-year of followup, which can be related with the lower severity of docetaxel CIPN and the fact that patients improved over this period.

Despite the contribution of the present study to an accurate characterization of the occurrence of CIPN among early-stage 
breast cancer patients, some limitations need to be addressed. Although nerve conduction studies (NCS) are considered the goal standard for CIPN diagnosis, the previous prospective studies using these methods to evaluate CIPN in breast cancer patients receiving chemotherapy with taxanes included a small number of breast cancer patients [34-36], reflecting the fact that NCS are time and resource consuming. Our study was based on a cohort of a large number of participants, assembled and followed in a clinical setting, which precludes complex evaluations such as NCS. Nevertheless, it is important to emphasize that we assessed CIPN using the TNSc, which incorporates not only subjective but also objective items $[25,27]$. A recent article from the chemotherapy-induced peripheral neuropathy outcome measure standardization study (CI-PeriNomS) concluded that vibratory sensation and light touch are associated with abnormal sural nerve amplitudes, suggesting that these components of neurological exam are reliable indicators of CIPN [37]; these two measures are included in TNSc score used in our study. We excluded patients with stage IV and those not submitted to surgical treatment, which limits the generalization to patients with more advanced disease. Furthermore, all patients were selected from the same institution, the Portuguese Institute of Oncology of Porto. However, this is the largest hospital providing care to oncological patients in the north of Portugal, treating patients from a wide geographical area, which may help to mitigate the latter limitation. Previous studies have shown that subclinical deficits in sensory function may be present among patients with colorectal cancer $[38,39]$ and myeloma [40, 41] even before initiating any therapy, and CIPN may correspond to an exacerbation of this preexisting condition. In our study, although all patients underwent a neurological examination before breast cancer treatment, to exclude clinical neuropathy, we did not perform quantitative sensory testing, and therefore, we cannot exclude the presence of subclinical deficits in sensory function before treatments. Future studies should address the role of these preexisting conditions as an effect modifier of the association between chemotherapy and CIPN. The participants in our study were followed for 6 months after the diagnosis of CIPN, and a longer follow-up will allow the comparison with studies with longer follow-up [42]. Previous studies addressed the effect of interventions to prevent CIPN [43-45], but no such exposures were observed in our cohort.

In conclusion, CIPN was frequent in this prospective cohort study of early-stage breast cancer patients and was strongly associated with docetaxel-based regimens. Symptoms persisted for at least 6 months in most patients, but severity was usually low; painful CIPN, and dose reduction due to CIPN were observed in a small number of patients, and CIPN had no impact on patient-reported outcomes. The results from this study are useful to support clinical decisions related with the use of docetaxel-based chemotherapy.

Funding The work of FF was supported by the "Fundação para a Ciência e a Tecnologia" (grant number SFRH/BD/92630/2013), and data management activities were supported by the Chair on Pain Medicine of the Faculty of Medicine, University of Porto and by the Grünenthal Foundation-Portugal.

Conflict of interest The authors declare that they have no competing interests.

Ethical approval All procedures performed in studies involving human participants were in accordance with the ethical standards of the institutional and national research committee and with the 1964 Helsinki declaration and its later amendments or comparable ethical standards.

\section{References}

1. Ferlay J, Soerjomataram I, Ervik M, Dikshit R, Eser S, Mathers C, Rebelo M, Parkin DM, Forman D, Bray F (2013) GLOBOCAN 2012 v1.0, Cancer incidence and mortality worldwide: IARC CancerBase No. 11. Lyon, France: International Agency for Research on Cancer. [http://globocan.iarc.fr/] (Accessed on 1 January 2015)

2. De Angelis R, Sant M, Coleman MP, Francisci S, Baili P, Pierannunzio D, Trama A, Visser O, Brenner H, Ardanaz E, Bielska-Lasota M, Engholm G, Nennecke A, Siesling S, Berrino F, Capocaccia R (2014) Cancer survival in Europe 1999-2007 by country and age: results of EUROCARE-5-a population-based study. Lancet Oncol 15(1):23-34

3. Howlader N, Noone A, Krapcho M, Garshell J, Neyman N, Altekruse S, et al. (2013) SEER Cancer Statistics Review, 19752011, National Cancer Institute. Bethesda, MD: SEER. Available from: [http://seer.cancer.gov/csr/1975_2011/] (Accessed on 1 November 2014)

4. Miltenburg NC, Boogerd W (2014) Chemotherapy-induced neuropathy: a comprehensive survey. Cancer Treat Rev 40(7):872-882

5. Hershman DL, Weimer LH, Wang A, Kranwinkel G, Brafman L, Fuentes D, Awad D, Crew KD (2011) Association between patient reported outcomes and quantitative sensory tests for measuring long-term neurotoxicity in breast cancer survivors treated with adjuvant paclitaxel chemotherapy. Breast Cancer Res Treat 125(3): 767-774

6. Eckhoff L, Knoop A, Jensen M, Ewertz M (2015) Persistence of docetaxel-induced neuropathy and impact on quality of life among breast cancer survivors. Eur J Cancer 51(3):292-300

7. Jaggi AS, Singh N (2012) Mechanisms in cancer-chemotherapeutic drugs-induced peripheral neuropathy. Toxicology 291(1-3):1-9

8. Park SB, Krishnan AV, Lin CS, Goldstein D, Friedlander M, Kiernan MC (2008) Mechanisms underlying chemotherapyinduced neurotoxicity and the potential for neuroprotective strategies. Curr Med Chem 15(29):3081-3094

9. Windebank AJ, Grisold W (2008) Chemotherapy-induced neuropathy. J Peripher Nerv Syst 13(1):27-46

10. Seretny M, Currie GL, Sena ES, Ramnarine S, Grant R, MacLeod MR, Colvin LA, Fallon M (2014) Incidence, prevalence, and predictors of chemotherapy-induced peripheral neuropathy: a systematic review and meta-analysis. Pain 155(12):2461-2470 
11. Ewertz M, Qvortrup C, Eckhoff L (2015) Chemotherapy-induced peripheral neuropathy in patients treated with taxanes and platinum derivatives. Acta Oncol 54(5):587-591

12. Kudlowitz D, Muggia F (2014) Clinical features of taxane neuropathy. Anti-Cancer Drugs 25(5):495-501

13. Rivera E, Cianfrocca M (2015) Overview of neuropathy associated with taxanes for the treatment of metastatic breast cancer. Cancer Chemother Pharmacol 75(4):659-670

14. De Iuliis F, Taglieri L, Salerno G, Lanza R, Scarpa S (2015) Taxane induced neuropathy in patients affected by breast cancer: literature review. Crit Rev Oncol Hematol

15. Vincenzi B, Frezza AM, Schiavon G, Spoto C, Silvestris N, Addeo R, Catalano V, Graziano F, Santini D, Tonini G (2013) Identification of clinical predictive factors of Oxaliplatin-induced chronic peripheral neuropathy in colorectal cancer patients treated with adjuvant Folfox IV. Support Care Cancer 21(5):1313-1319

16. Ramanathan RK, Rothenberg ML, de Gramont A, Tournigand C, Goldberg RM, Gupta S, Andre T (2010) Incidence and evolution of oxaliplatin-induced peripheral sensory neuropathy in diabetic patients with colorectal cancer: a pooled analysis of three phase III studies. Ann Oncol 21(4):754-758

17. de la Morena BP, Conesa MA, Gonzalez-Billalabeitia E, Urrego E, Garcia-Garre E, Garcia-Martinez E, Poves MZ, Vicente V, de la Pena FA (2015) Delayed recovery and increased severity of paclitaxel-induced peripheral neuropathy in patients with diabetes. J Natl Compr Cancer Netw 13(4):417-423

18. Uwah AN, Ackler J, Leighton JC Jr, Pomerantz S, Tester W (2012) The effect of diabetes on oxaliplatin-induced peripheral neuropathy. Clin Colorectal Cancer 11(4):275-279

19. Pereira S, Fontes F, Sonin T, Dias T, Fragoso M, Castro-Lopes J, Lunet N (2014) Neurological complications of breast cancer: study protocol of a prospective cohort study. BMJ Open 4(10), e006301

20. Freitas S, Simoes MR, Alves L, Santana I (2011) Montreal cognitive assessment (MoCA): normative study for the Portuguese population. J Clin Exp Neuropsychol 33(9):989-996

21. Aaronson NK, Ahmedzai S, Bergman B, Bullinger M, Cull A, Duez NJ, Filiberti A, Flechtner H, Fleishman SB, de Haes JC et al (1993) The European Organization for Research and Treatment of Cancer QLQ-C30: a quality-of-life instrument for use in international clinical trials in oncology. J Natl Cancer Inst 85(5):365-376

22. Buysse DJ, Reynolds CF, Monk TH, Berman SR, Kupfer DJ (1989) The Pittsburgh sleep quality index: a new instrument for psychiatric practice and research. Psychiatry Res 28(2):193-213

23. Zigmond AS, Snaith RP (1983) The hospital anxiety and depression scale. Acta Psychiatr Scand 67(6):361-370

24. CTCAE (2010) Cancer Therapy Evaluation Program, Common terminology criteria for adverse events, version 4.0. DCTD, NCI, NIH, DHHS, [http://ctep.cancer.gov/] (Accessed on 1 January 2012).

25. Cornblath DR, Chaudhry V, Carter K, Lee D, Seysedadr M, Miernicki M, Joh T (1999) Total neuropathy score: validation and reliability study. Neurology 53(8):1660-1664

26. Treede RD, Jensen TS, Campbell JN, Cruccu G, Dostrovsky JO, Griffin JW, Hansson P, Hughes R, Nurmikko T, Serra J (2008) Neuropathic pain: redefinition and a grading system for clinical and research purposes. Neurology 70(18):1630-1635

27. Griffith KA, Merkies IS, Hill EE, Cornblath DR (2010) Measures of chemotherapy-induced peripheral neuropathy: a systematic review of psychometric properties. J Peripher Nerv Syst 15(4):314325

28. Lee JJ, Swain SM (2006) Peripheral neuropathy induced by microtubule-stabilizing agents. J Clin Oncol 24(10):1633-1642

29. Rowinsky EK, Chaudhry V, Cornblath DR, Donehower RC (1993) Neurotoxicity of taxol. J Natl Cancer Inst Monogr 15:107-115
30. Eckhoff L, Knoop AS, Jensen MB, Ejlertsen B, Ewertz M (2013) Risk of docetaxel-induced peripheral neuropathy among 1,725 Danish patients with early stage breast cancer. Breast Cancer Res Treat 142(1):109-118

31. Eckhoff L, Nielsen M, Moeller S, Knoop A (2011) TAXTOX-a retrospective study regarding the side effects of docetaxel given as part of the adjuvant treatment to patients with primary breast cancer in Denmark from 2007 to 2009. Acta Oncol 50(7):1075-1082

32. Quasthoff S, Hartung HP (2002) Chemotherapy-induced peripheral neuropathy. J Neurol 249(1):9-17

33. Mols F, Beijers T, Vreugdenhil G, van de Poll-Franse L (2014) Chemotherapy-induced peripheral neuropathy and its association with quality of life: a systematic review. Support Care Cancer 22(8):2261-2269

34. Pace A, Nistico C, Cuppone F, Bria E, Galie E, Graziano G, Natoli G, Sperduti I, Jandolo B, Calabretta F, Tomao S, Terzoli E (2007) Peripheral neurotoxicity of weekly paclitaxel chemotherapy: a schedule or a dose issue? Clin Breast Cancer 7(7):550-554

35. Argyriou AA, Polychronopoulos P, Koutras A, Iconomou G, Gourzis P, Assimakopoulos K, Kalofonos HP, Chroni E (2006) Is advanced age associated with increased incidence and severity of chemotherapy-induced peripheral neuropathy? Support Care Cancer 14(3):223-229

36. Freilich RJ, Balmaceda C, Seidman AD, Rubin M, DeAngelis LM (1996) Motor neuropathy due to docetaxel and paclitaxel. Neurology 47(1):115-118

37. Griffith KA, Dorsey SG, Renn CL, Zhu S, Johantgen ME, Cornblath DR, Argyriou AA, Cavaletti G, Merkies IS, Alberti P, Postma TJ, Rossi E, Frigeni B, Bruna J, Velasco R, Kalofonos HP, Psimaras D, Ricard D, Pace A, Galie E, Briani C, Dalla Torre C, Faber CG, Lalisang RI, Boogerd W, Brandsma D, Koeppen S, Hense J, Storey DJ, Kerrigan S, Schenone A, Fabbri S, Valsecchi MG (2014) Correspondence between neurophysiological and clinical measurements of chemotherapy-induced peripheral neuropathy: secondary analysis of data from the CI-PeriNomS study. J Peripher Nerv Syst 19(2):127-135

38. de Carvalho BM, Kosturakis AK, Eng C, Wendelschafer-Crabb G, Kennedy WR, Simone DA, Wang XS, Cleeland CS, Dougherty PM (2014) A quantitative sensory analysis of peripheral neuropathy in colorectal cancer and its exacerbation by oxaliplatin chemotherapy. Cancer Res 74(21):5955-5962

39. Boyette-Davis JA, Eng C, Wang XS, Cleeland CS, WendelschaferCrabb G, Kennedy WR, Simone DA, Zhang H, Dougherty PM (2012) Subclinical peripheral neuropathy is a common finding in colorectal cancer patients prior to chemotherapy. Clin Cancer Res 18(11):3180-3187

40. Vichaya EG, Wang XS, Boyette-Davis JA, Mendoza TR, He Z, Thomas SK, Shah N, Williams LA, Cleeland CS, Dougherty PM (2013) Subclinical pretreatment sensory deficits appear to predict the development of pain and numbness in patients with multiple myeloma undergoing chemotherapy. Cancer Chemother Pharmacol 71(6): 1531-1540

41. Kosturakis AK, He Z, Li Y, Boyette-Davis JA, Shah N, Thomas SK, Zhang H, Vichaya EG, Wang XS, Wendelschafer-Crabb G, Kennedy WR, Simone DA, Cleeland CS, Dougherty PM (2014) Subclinical peripheral neuropathy in patients with multiple myeloma before chemotherapy is correlated with decreased fingertip innervation density. J Clin Oncol 32(28):3156-3162

42. Osmani K, Vignes S, Aissi M, Wade F, Milani P, Levy BI, Kubis N (2012) Taxane-induced peripheral neuropathy has good long-term prognosis: a 1 - to 13-year evaluation. J Neurol 259(9):1936-1943

43. Davis ID, Kiers L, MacGregor L, Quinn M, Arezzo J, Green M, Rosenthal M, Chia M, Michael M, Bartley P, Harrison L, Daly M (2005) A randomized, double-blinded, placebo-controlled phase II trial of recombinant human leukemia inhibitory factor (rhuLIF, 
emfilermin, AM424) to prevent chemotherapy-induced peripheral neuropathy. Clin Cancer Res 11(5):1890-1898

44. Leal AD, Qin R, Atherton PJ, Haluska P, Behrens RJ, Tiber CH, Watanaboonyakhet P, Weiss M, Adams PT, Dockter TJ, Loprinzi CL (2014) North Central Cancer Treatment Group/Alliance trial N08CA - the use of glutathione for prevention of paclitaxel/ carboplatin-induced peripheral neuropathy: a phase 3 randomized, double-blind, placebo-controlled study. Cancer 120(12):1890 1897
45. Hershman DL, Unger JM, Crew KD, Minasian LM, Awad D, Moinpour CM, Hansen L, Lew DL, Greenlee H, Fehrenbacher L, Wade JL 3rd, Wong SF, Hortobagyi GN, Meyskens FL, Albain KS (2013) Randomized double-blind placebo-controlled trial of acetylL-carnitine for the prevention of taxane-induced neuropathy in women undergoing adjuvant breast cancer therapy. J Clin Oncol 31(20):2627-2633 